\title{
OS PROCESSOS DESENCADEADOS PELAS COOPERATIVAS E A REORGANIZAÇÃO ESPACIAL NAS PEQUENAS CIDADES DO TERRITÓRIO DO SISAL (1990-2014)
}

\author{
Fabrício Oliveira Diass e Edinusia Moreira Carneiro Santos ${ }^{2}$ \\ 1. Bolsista PIBIC/CNPq, Graduando em Geografia, Universidade Estadual de Feira de \\ Santana, \\ e-mail: fabricio_geofsa@hotmail.com \\ 2. Orientadora, Departamento de Ciências Humanas e Filosofia , Universidade Estadual de Feira de \\ Santana, \\ e-mail: nusiafs@hotmail.com
}

PALAVRAS-CHAVE: ESPAÇO, COOPERATIVAS, ECONOMIA,.

\section{INTRODUÇÃO}

O Território do Sisal é um espaço dinâmico socioeconomicamente que desde décadas passadas vem passando por várias mudanças no que diz respeito a economia, a politica e aos movimentos sociais, estabelecendo, assim, maneiras para organizar o espaço.

Dessa forma, é notável a grande importância das cooperativas para esse processo de organização espacial de nove pequenas cidades do território do Sisal (Cansanção, Itiúba, Monte Santo, Nordestina, Queimadas, Retirolândia, São Domingos, Tucano e Valente), pois, as cooperativas são entidades composta por trabalhadores que se associam para garantir direitos e benefícios econômicos e sociais com uma só filosofia, o bem estar dos associados.

Diante da atualidade, onde o modo de produção capitalista propõe apenas a filosofia do lucro para uma pequena parcela da sociedade segregando a outra parcela, as cooperativas são uma força a ser considerada no momento atual, fazendo com que, seja uma também força descentralizadora do capital dominante.

Assim, o que pode ser discutido nesse trabalho é como as cooperativas, principalmente dos municípios de São Domingos e Valente desencadearam processos para reorganizar esses espaços. Sendo que, esse estudo é baseado no catálogo do cooperativismo produzido por uma secretaria do governo do estado da Bahia a SETRE (Secretaria do Trabalho, Emprego, Renda e Esporte) em 2012, a fim de organizar dados e informações de todas as cooperativas do estado da Bahia.

Dessa maneira, essas cooperativas serão identificadas e caracterizadas para assim concluirmos a importância do cooperativismo para reorganização desses espaços.

\section{METODOLOGIA}

Os procedimentos metodológicos aplicados à pesquisa iniciaram-se primeiramente com a revisão de literatura para posteriormente ser confeccionado o referencial teórico.

Assim em momento ulterior foram levantados dados secundários, análise documental em alguns órgãos públicos, a construção de mapas e tabelas. Por último houve a aplicação de questionário nas cooperativas encontradas nos munícipios de São Domingos e Valente.

Para ressaltar, a aplicação de questionário só ocorreu nos dois municípios que possuíam a maior quantidade de cooperativas, os municípios de São Domingos e Valente. Pois, com a demora nas respostas e depois a falta de resposta com as listas das cooperativas pela OCB (Organização das Cooperativas do Brasil), o tempo ficou muito curto.

\section{RESULTADO E DISCUSSÃO}


Segundo o catálogo do cooperativismo criado pela SETRE (2012), os municípios e cooperativas do Território do Sisal apresentam grandes diferenças ao se tratar da quantidade de cooperativas e do tipo de cooperativa que são encontradas. Os tipos mais comuns encontradas ao analisar os dados foram as cooperativas de trabalho, mineração, produção, agropecuária, transporte, serviço, infraestrutura e crédito.

Essa distribuição diz respeito as necessidades que cada município tem de se organizar e criar sua cooperativas. É verificável um número expressivo de cooperativas em alguns municípios como São Domingos e Valente e em contra partida uma acentuada redução em outros, o que pode indicar que a partir do número e tipo de cooperativa pode-se fazer uma melhor analise de como essas cooperativas estão estruturadas nesses municípios.

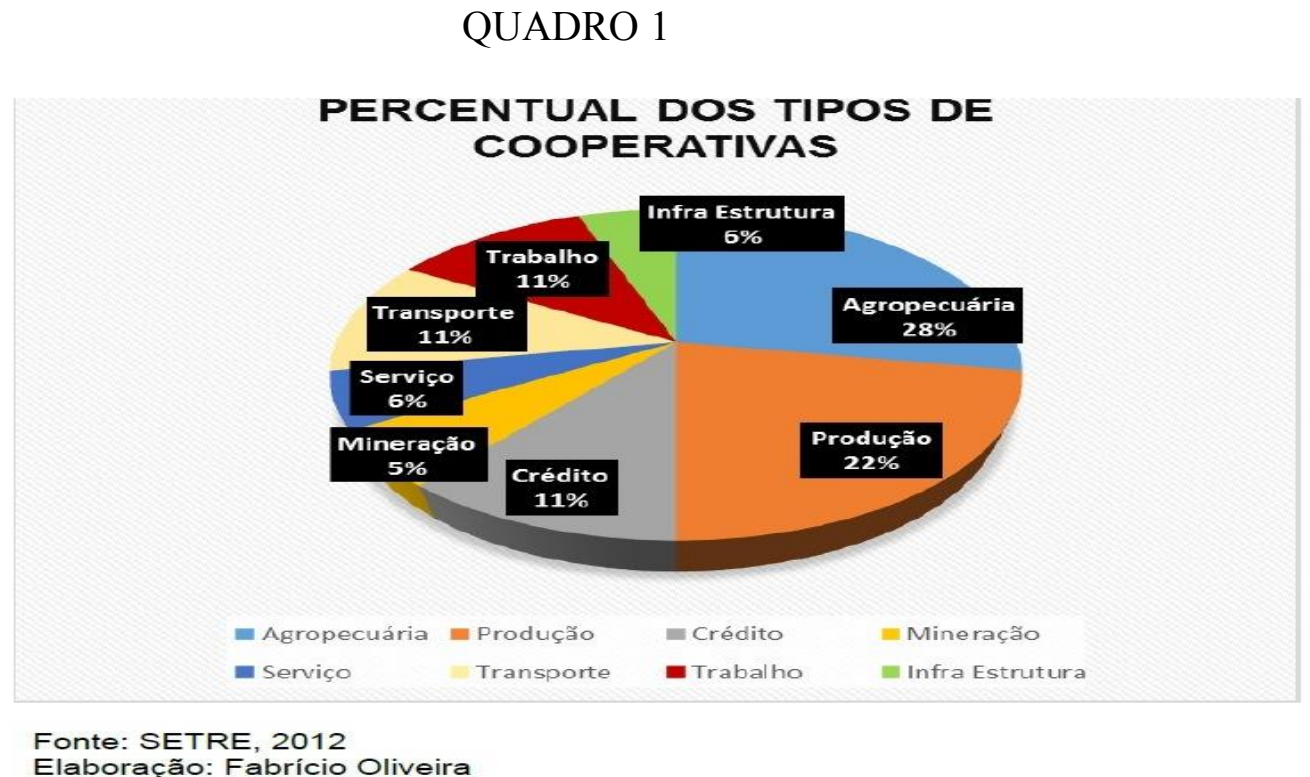

No quadro 1, estão presentes vários tipos de cooperativas e analisados os percentuais para cada cidade. Observa-se que nesse quadro as cooperativas do tipo agropecuárias e produção, estão presentes em quase todos os municípios, indicando que esse tipo de cooperativa exerce um papel fundamental para economia dessas cidades.

Algumas cidades apresentam semelhanças no tipo de serviço oferecido, por exemplo, observa-se no (quadro 2), que as cidades de Cansanção, Itiúba, Nordestina e Queimadas apontam principalmente cooperativas cujas atividades são do tipo agropecuária e produção.

\section{QUADRO 02}

AS NOVE PEQUENAS CIDADES E AS COOPERATIVAS DO TERRITÓRIO DO SISAL, 2012.

\begin{tabular}{|c|c|c|c|c|c|}
\hline $\begin{array}{l}\text { MUNICIPIOS } \\
\text { COOPERATIVAS }\end{array}$ & CANSANÇĀO & ITIUBBA & $\begin{array}{l}\text { MONTE } \\
\text { SANTO }\end{array}$ & NORDESTINA & QUEIMADAS \\
\hline AGROPECUARIA & 1 & 1 & & 1 & 2 \\
\hline CRÉDITO & & & & & \\
\hline $\begin{array}{l}\text { INFRA } \\
\text { ESTRUTURA }\end{array}$ & & & 1 & & \\
\hline MINERAÇÃO & & & & 1 & \\
\hline PRODUÇÃO & 1 & & 1 & 1 & 1 \\
\hline SERVIÇOS & & & & & \\
\hline TRANSPORTE & 1 & & & & \\
\hline TRABALHO & & 1 & & & \\
\hline TOTAL & 3 & 2 & 2 & 3 & 3 \\
\hline
\end{tabular}




\begin{tabular}{|c|c|c|c|c|c|}
\hline $\begin{array}{l}\text { MUNICIPIOS } \\
\text { COOPERATIVAS }\end{array}$ & RETIROLÄNDIA & $\begin{array}{l}\text { SÄO } \\
\text { DOMINGOS }\end{array}$ & TUCANO & VALENTE & \\
\hline AGROPECUARIA & & 4 & 1 & 2 & \\
\hline CREDITO & & 1 & & 1 & \\
\hline $\begin{array}{l}\text { INFRA } \\
\text { ESTRUTURA } \\
\text { MINERAÇAO }\end{array}$ & & & & & \\
\hline PRODUÇÃO & 2 & 2 & 1 & 3 & \\
\hline SERVIÇOS & & & & 1 & \\
\hline TRANSPORTE & & 1 & & & \\
\hline TRABALHO & & 1 & & & \\
\hline TOTAL & 2 & 11 & 2 & 7 & \\
\hline
\end{tabular}

Fonte: SETRE, 2012

Elaboração: Fabrício Oliveira

$\mathrm{Na}$ atualidade, as cooperativas das duas pequenas cidades do Território do Sisal, que possuíam o maior número de cooperativas fundamentado pelo Catálogo da SETRE, São Domingos e Valente, respectivamente 11 e 7 cooperativas, na prática, através do trabalho de campo não foram possíveis identificá-las.

As cooperativas do presente estudo estão localizadas nos municípios de São Domingos e Valente, como pode ser verificado no mapa (3). Nesses dois municípios foram encontradas as maiores discrepâncias no sentido que em 2012 era verificado uma quantidade de 18 cooperativas ativas, mais em 2016 foi observada através do trabalho de campo apenas 04, duas cooperativas para cada município.

\section{FIGURA 3}

\section{Mapa de Localização dos Municípios de São Domingos e Valente}

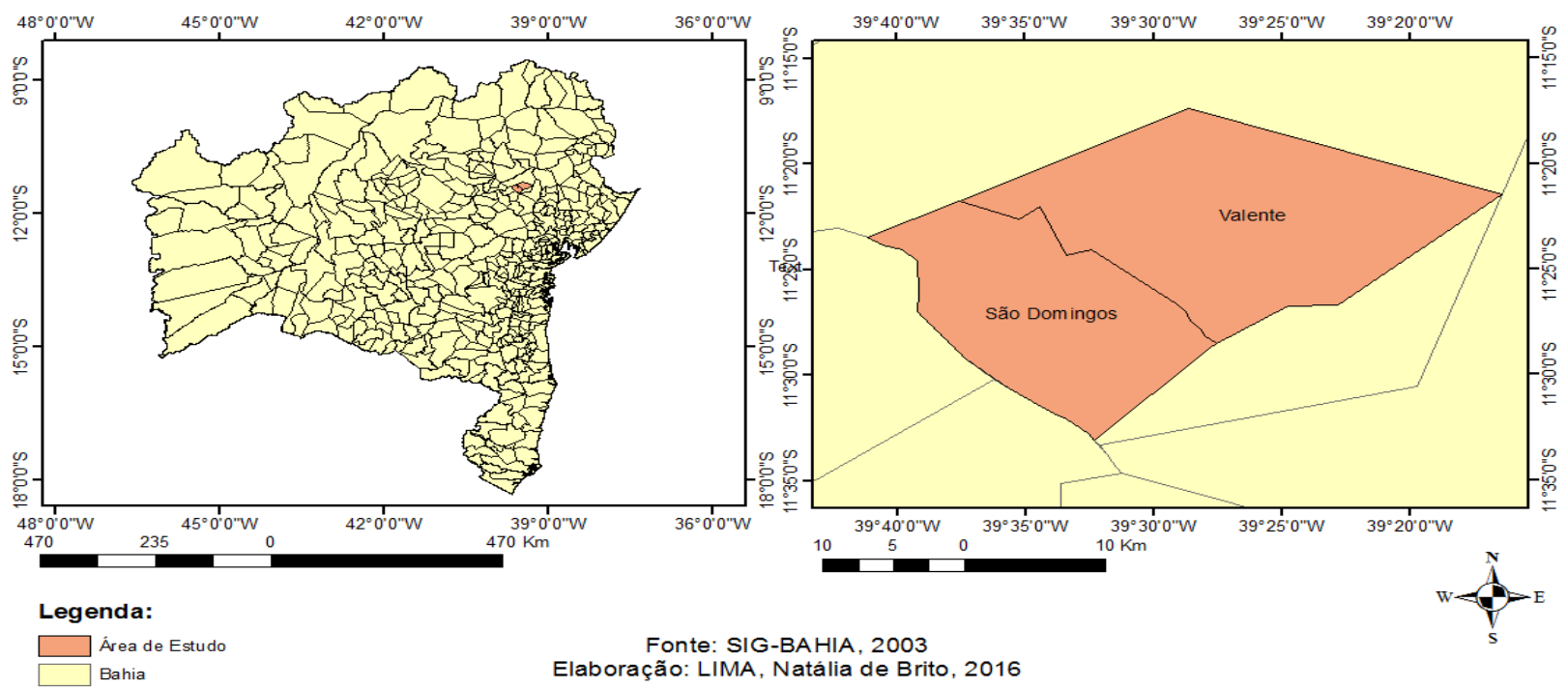

Dessa maneira foi observado que a COOPERSERTÃO (Cooperativa Mista dos Produtores de São Domingos) cooperativa agropecuária, a COOPERAFIS (Cooperativa Regional de Artesãs Fibras do Sertão) cooperativa de produção e outra cooperativa que alterou a estrutura econômica e social de algumas cidades, como por exemplo, a COOPERE (Cooperativa de crédito rural do semiárido da Bahia) que é uma cooperativa de crédito, criada nos anos 1960 a partir da APAEB (Associação de Desenvolvimento Sustentável e Solidária da Região Sisaleira) para emprestar dinheiro aos pequenos produtores com juros mais baixos, 
livrando-os dos altos juros empregados pelos bancos convencionais. A COOPERE está distribuída por várias cidades do Território do Sisal, sendo assim, uma das mais importantes.

\section{CONSIDERAÇÕES FINAIS}

A discussão sobre o cooperativismo nas pequenas cidades do Território do Sisal, precisamente onde foi feito o recorte espacial para o estudo dos municípios de São Domingos e Valente, foi de bastante relevância para a compreensão de como essas cooperativas são organizadas socioespacialmente.

Foi verificado o quão complexo pode ser analisar, caracterizar e sintetizar como as cooperativas se organizam para tentar permanecer a sua filosofia cooperativista no espaço. Assim, pôde ser sintetizado que as cooperativas independentemente da sua tipologia são instituições organizadas e que estarão sempre realizando suas atividades de cunho econômico e social tentando diminuir as desigualdades da força de produção capitalista, essa, que molda os espaços os fragmentando com desigualdade e poder.

\section{REFERÊNCIAS BIBLIOGRÁFICAS}

AUGER, Michel; SAUCEDO, Daniele; NICOLAZZI JUNIOR, Norton Frehse. Os caminhos do cooperativismo. Curitiba: UFPR, 2001.

ALVES, Francisco de Assis; MILANI, Imaculada Abenante. Sociedades cooperativas: regime jurídico e procedimentos legais para sua constituição e funcionamento. 2. ed São Paulo Juarez de Oliveira, 2003.

CARLOS, Ana Fani A. A Cidade.4.ed São Paulo: Contexto, 1999

CARLOS, Ana Fani A. A condição espacial. Editora Contexto, 2011.

CORRÊA, R. L. rede urbana: reflexões, hipóteses e questionamentos sobre um tema negligenciado. Revista Cidades, Presidente Prudente, v. 1, n. 1, p. 65-78. jan./jun. 2004.

DOLLFUS, Olivier. O espaço geográfico. 2. ed Rio de Janeiro, RJ: Difel, 1975.

ENDLICH, Ângela Maria. Pensando os papéis e significados das pequenas cidades do Noroeste do Paraná. 2006.

FIGUEIREDO, Vilma Dominga Monfardini. Pequenos municípios e pequenas cidades do estado do Rio Grande do Sul: contrastes, perfil do desenvolvimento e de qualidade de vida, 1980-2000. 2008.

FRESCA, Tânia Maria. Centros locais e pequenas cidades: diferenças necessárias.

Mercator, v. 9, n. 20, 2010.

FROES, Oswaldo. Cooperativas de educação. São Paulo: Mackenzie: Forense Universitária, 2001.

GEORGE, P. Pour une étudesystématiquedespetitesvilles. Annales de Géographie, n. 424,1968, p. 745.

MLADENATZ, Gromoslav. História das doutrinas cooperativistas. Brasília:

Confebras, 2003. 
